\title{
Karyotypes and Ag-NORs of the mussels Mytilus californianus and M. trossulus from the Pacific Canadian coast
}

\author{
A. Martínez-Lage ${ }^{\mathrm{a}}$, A. González-Tizón ${ }^{\mathrm{a}}, \mathrm{J}$. Ausiób $^{\mathrm{b}}, \mathrm{J}_{\text {. Méndez }}{ }^{\mathrm{a}^{*}}$ \\ ${ }^{a}$ Departamento de Biología Celular y Molecular, Facultad de Ciencias, Universidad de La Coruña, 15071 La \\ Coruña, Spain \\ ${ }^{\mathrm{b}}$ Department of Biochemistry and Microbiology, University of Victoria, Victoria, BC V8W 3P6, Canada
}

Aquaculture, volume 153, issue 3-4, pages 239-249, 01 july 1997

Accepted 30 december 1996, available online 05 january 1998

\section{How to cite:}

Martínez-Lage, A., González-Tizón, A., Ausió, J. and J. Méndez. 1997. Karyotypes and Ag-NORs of the mussels Mytilus californianus and M. trossulus from the Pacific Canadian coast. Aquaculture, 153: (3-4), 239-249. DOI: 10.1016/S0044-8486(97)00028-8

\section{Abstract}

The karyotypes and the nucleolus organizer regions (NORs) of $M$. californianus and M. trossulus from the Pacific coast are reported here for the first time. The karyotypes show seven metacentric and seven submetacentric chromosome pairs. In M. californianus, nucleolar organizer regions appear located in terminal position on the short arm of one metacentric chromosome pair and of one submetacentric. A third Ag-NOR is located near to the telomere region on the short arm of one submetacentric. In M. trossulus, AgNORs appear terminally located on the short arms of two metacentric chromosome pairs and on the short and long arms of one submetacentric. The comparison of the karyotypes and Ag-NORs among the species of mussels from the Pacific and European coasts shows remarkable differences.

Keywords: Mytilus californianus; Mytilus trossulus; chromosome; karyotype; NOR.

\section{Introduction}

For several years, the taxonomy of the genus Mytilus has been the subject of an important controversy. Despite a great number of studies on morphological, electrophoretic (allozyme) and morphometric parameters, the taxonomic status of the genus Mytilus remains unclear. Morphological characters are remarkably variable in mussels, but electrophoretic analysis of different allozymes has allowed the recognition of five or six species belonging to the genus Mytilus: M. edulis, M. galloprovincialis, M. trossulus, M. desolationis, M. californianus and, perhaps, M. coruscus (McDonald and Koehn, 1988; McDonald et al., 1991; Gosling, 1992; Seed, 1992). The application of cytogenetic techniques has supplied information about the genetics of this genus, and it is obvious that it opens new possibilities to clarify the taxonomic status. Chromosome number and morphology have been described in M. edulis, M. galloprovincialis, M. trossulus and M. desolationis (Ahmed and Sparks, 1970; Ieyama, 1983; Moynihan and Mahon, 1983; Thiriot-Quiévreux, 1984; Dixon and Flavell, 1986; Pasantes et al., 1990; Insua et al., 1994).

Staining of nucleolar organizer regions (NORS) and/or C-banding were carried out in some of these Mytilus species (Dixon et al., 1986; Cornet, 1993; Insua et al., 1994; Martinez-Expósito et al., 1994). However, it is very complicated to obtain other chromosome banding patterns in molluscs. Méndez et al. (1990) described a G-banding pattern in M. galloprovincialis chromosomes employing a 2 x SSC solution. At the moment, only 
Martínez-Lage et al. (1994) have widely characterized the karyotype of M. galloprovincialis after C-banding, fluorochrome and restriction endonuclease treatments. Furthermore, they classified and identified the chromosome complement of this species by means of G-banding obtained after digestion with trypsin enzyme. The same authors (Martínez-Lage et al., 1995) described the existence of changes in the constitutive heterochromatin of M. edulis, M. galloprovincialis and M. trossulus on the basis of C-, NOR and fluorescence banding patterns. The detection of different chromosome markers allows the identification of these three mussel species. We must point out that all these cytogenetic studies were carried out in mussels distributed throughout the European coasts, with the exception of $M$. desolationis samples (Kerguelen Isles) analyzed by Thiriot-Quiévreux, 1984 and the population of M. galloprovincialis studied by Ieyama (1983) in Seto (Japan).

The Pacific coast of Canada and North America is inhabited by three species of the mussel Mytilus: M. galloprovincialis Lamarck, 1819, M. californianus Conrad, 1837 and M. trossulus Gould, 1850. M. californianus is easily identified by the presence of radiating ribs on the shell (Soot-Ryen, 1955) and because it inhabits exposed shores along the coast (Seed, 1976). There is little information about M. californianus. To our knowledge, only Ahmed and Sparks (1970) have studied the chromosome number and morphology from primary oocytes and embryos of this species. We have not found references to electrophoretic data. Perhaps, because the specific status of $M$. californianus has never been in question (Gosling, 1992). Furthermore, Ahmed and Sparks (1970) have analyzed the chromosome number and morphology of M. edulis (ecotype M. trossulus). Allozyme data about M. trossulus from the Pacific coast were reported by McDonald and Koehn (1988); McDonald et al. (1991) and Sarver and Foltz (1993).

In this work, we analyzed the karyotypes of $M$. californianus and $M$. trossulus from the Canadian Pacific coast, by means of karyotyping and Ag-NOR staining in an attempt to provide new data on the taxonomy of these species.

\section{Materials and methods}

Mussels were collected in two localities of Vancouver Island, British Columbia, (Canadian Pacific coast): $M$. trossulus from Esquimalt Lagoon and M. californianus from Point No Point. In the laboratory, animals were fed with Isochrisis galbana microalgae for 10 days. Then, mussels were treated with $0.005 \%$ colchicine for 6-8 $\mathrm{h}$; gills were dissected and $0.56 \% \mathrm{KC} 1$ solution was added for $15 \mathrm{~min}$. Fixation was carried out in ethanol: glacial acetic acid (3:1) involving four changes of 10, 10, 20 and $20 \mathrm{~min}$ at $4^{\circ} \mathrm{C}$. Fixed cells were dissociated in a $45 \%$ acetic acid: water solution and were dropped onto heated slides at $43^{\circ} \mathrm{C}$. Metaphases were stained with $4 \%$ Giemsa in phosphate buffer $\mathrm{pH} 6.8$ and NOR silver staining was performed according to Howell and Black (1980). Finally, the metaphases were photographed with a Nikon Optiphot microscope.

\section{Chromosome analysis}

Karyotypes were arranged by decreasing size and classified according to the centromeric index (Levan et al., 1964). Measurements of the total chromosome length and chromosome long arms length were carried out employing a Magiscan image analysis. Total chromosome length and chromosomal long arm length were measured in 10 metaphases of gill tissue from each one of the population studied. Mean value of the length of the chromosome long arms and the mean value for their total chromosome length were calculated for each one of the chromosome pairs. The relative length (100 X chromosome length/ total haploid length) and the centromeric index (100 X length of short arm/ total chromosome length) were also calculated. Finally, we calculated the mean value and the standard error (standard deviation/number of individuals) $1 / 2$ of the relative lengths and centromeric index. 


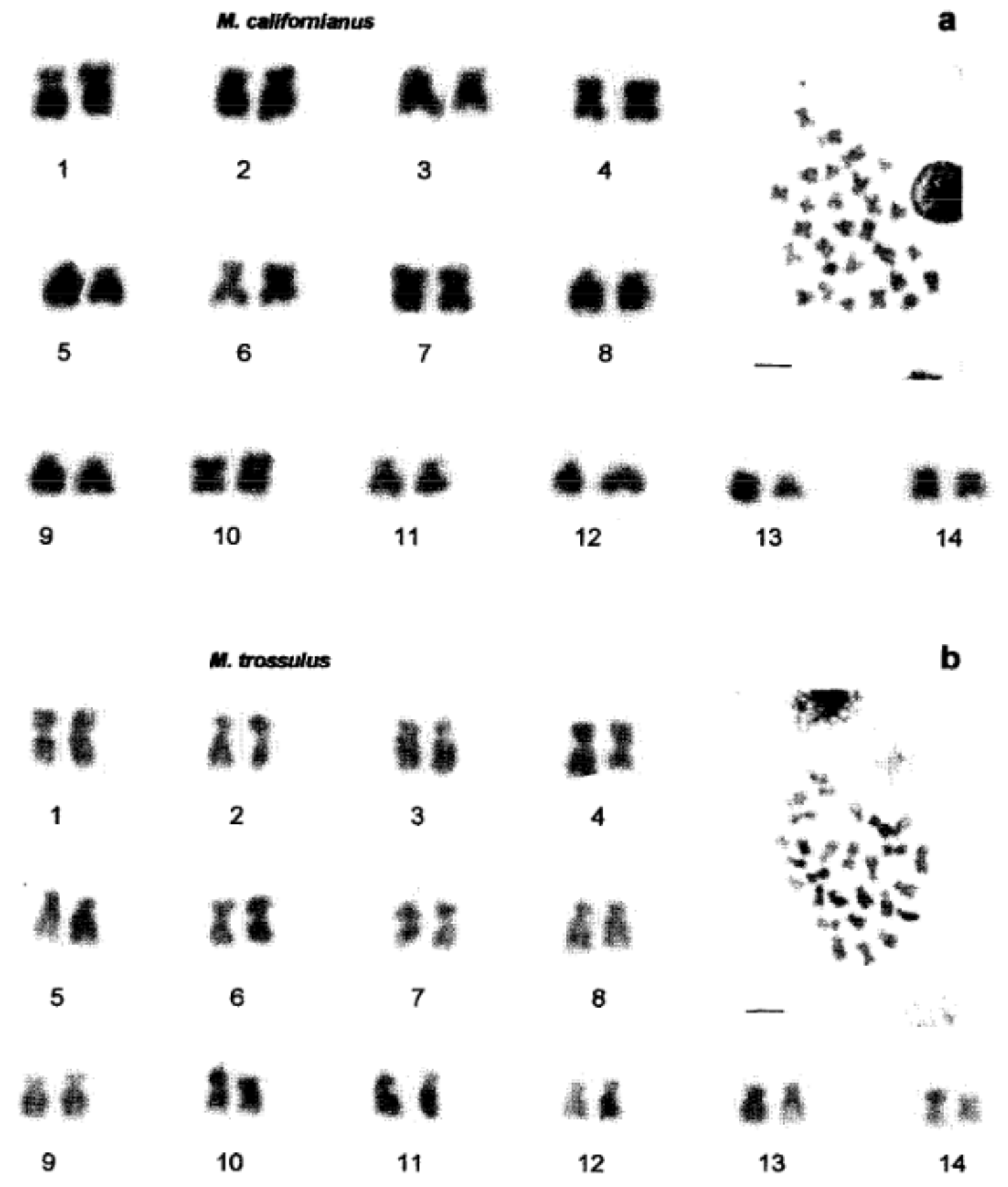

Figure 1. Giemsa stained karyotypes of (a) Mytilus californianus and (b) M. trossulus. Bar $=5 \mu \mathrm{m}$

\section{Results}

A diploid complement of 28 chromosomes was confirmed for M. californianus and M. trossulus from the Canadian Pacific coast (Fig. 1). Table 1 gives relative length and centromeric index values. Relative length values varied from 9.37 to 5.60 for $M$. californianus and 9.53 to 5.61 for $M$. trossulus. There is only one chromosome pair (chromosome No. 6 from both species) with a centromeric index value which varies between the submetacentric and subtelocentric categories. In each one of the metaphases analyzed for $M$. californianus and $M$. trossulus, karyotypes show seven metacentric and seven submetacentric chromosome pairs (Fig. 1, Table 1). Rarely, in some metaphases, we have observed subtelocentric chromosomes, but we have never detected any telocentric chromosomes. 
NORs were analyzed in 103 metaphases observed from a total of 23 individuals of M. californianus (Table 2). We have observed three silver-stained NORs located on chromosome pairs Nos. 3, 5 and 12 (Fig. $2 a$ ). Terminal NORs appear on the short arm of chromosome Nos. 3 and 12; the NOR located on chromosome No. 5 appears near to the telomere of the short arm (subterminal position) (Fig. 3a). A variable number of one to six Ag-NORs per cell was observed (Fig. 4, Table 2), with two NORs the most frequent case. The analysis of 37 metaphases on 11 individuals allowed us to detect that the Ag-NOR which shows high activity is located on chromosome No. 12. The NOR activity of chromosomes Nos. 3 and 5 is very similar and lower than the activity of the NOR located on chromosome No. 12 (Fig. $5 a$ ).

Table 1. Chromosome measurements and classification of M. californianus and M. trossulus populations

\begin{tabular}{lllllll}
\hline & \multicolumn{7}{l}{ M. californianus } & \multicolumn{7}{l}{ M. trossulus } \\
\cline { 2 - 7 } C.N. & Rel. Leng. & Cen. Ind. & Clas. & Rel. Leng. & Cen. Ind. & Clas. \\
\hline 1 & $9.37 \pm 0.21$ & $40.36 \pm 1.50$ & $\mathrm{~m}$ & $9.53 \pm 0.24$ & $43.82 \pm 0.98$ & $\mathrm{~m}$ \\
2 & $8.41 \pm 0.21$ & $28.96 \pm 0.97$ & $\mathrm{sm}$ & $8.44 \pm 0.30$ & $29.03 \pm 0.89$ & $\mathrm{sm}$ \\
3 & $8.37 \pm 0.17$ & $37.88 \pm 0.91$ & $\mathrm{~m}$ & $7.93 \pm 0.23$ & $44.12 \pm 1.69$ & $\mathrm{~m}$ \\
4 & $7.80 \pm 0.11$ & $44.87 \pm 1.07$ & $\mathrm{~m}$ & $7.63 \pm 0.18$ & $43.20 \pm 1.03$ & $\mathrm{~m}$ \\
5 & $7.57 \pm 0.16$ & $28.28 \pm 1.24$ & $\mathrm{sm}$ & $7.54 \pm 0.21$ & $26.99 \pm 0.86$ & $\mathrm{sm}$ \\
6 & $7.36 \pm 0.16$ & $26.08 \pm 1.75$ & $\mathrm{sm} / \mathrm{st}$ & $7.35 \pm 0.18$ & $25.25 \pm 1.12$ & $\mathrm{sm} / \mathrm{st}$ \\
7 & $7.21 \pm 0.18$ & $44.10 \pm 1.15$ & $\mathrm{~m}$ & $7.00 \pm 0.20$ & $26.16 \pm 0.91$ & $\mathrm{sm}$ \\
8 & $7.15 \pm 0.21$ & $42.24 \pm 1.32$ & $\mathrm{~m}$ & $6.92 \pm 0.20$ & $27.97 \pm 1.18$ & $\mathrm{sm}$ \\
9 & $6.57 \pm 0.12$ & $43.64 \pm 1.30$ & $\mathrm{~m}$ & $6.90 \pm 0.24$ & $43.16 \pm 1.38$ & $\mathrm{~m}$ \\
10 & $6.54 \pm 0.12$ & $27.71 \pm 0.70$ & $\mathrm{sm}$ & $6.85 \pm 0.19$ & $43.79 \pm 0.85$ & $\mathrm{~m}$ \\
11 & $6.25 \pm 0.12$ & $28.69 \pm 0.74$ & $\mathrm{sm}$ & $6.33 \pm 0.18$ & $42.67 \pm 1.95$ & $\mathrm{~m}$ \\
12 & $6.06 \pm 0.14$ & $31.33 \pm 1.05$ & $\mathrm{sm}$ & $6.27 \pm 0.24$ & $30.01 \pm 1.38$ & $\mathrm{sm}$ \\
13 & $5.74 \pm 0.25$ & $43.38 \pm 0.72$ & $\mathrm{~m}$ & $5.71 \pm 0.17$ & $28.69 \pm 0.94$ & $\mathrm{sm}$ \\
14 & $5.60 \pm 0.16$ & $28.46 \pm 1.01$ & $\mathrm{sm}$ & $5.61 \pm 0.25$ & $45.94 \pm 0.72$ & $\mathrm{~m}$ \\
\hline
\end{tabular}

C.N.: Chromosome number; Rel. Leng.: Relative length; Cen. Ind.: Centromeric Index;

Clas.: Classification; m: metacentric; sm: submetacentric; st: subtelocentric.

Table 2. Summary of Ag-NORs in M. californianus and M. trossulus

\begin{tabular}{|c|c|c|c|c|c|c|c|c|c|}
\hline \multirow[t]{2}{*}{ Species } & \multicolumn{7}{|c|}{ No. Ag-NORs per metaphase } & \multirow[t]{2}{*}{ Metaphases } & \multirow[t]{2}{*}{ Individuals } \\
\hline & 0 & 1 & 2 & 3 & 4 & 5 & 6 & & \\
\hline \multicolumn{10}{|l|}{ M. californianus } \\
\hline Pair 3 & 14 & 15 & 8 & - & - & - & - & 37 & 11 \\
\hline Pair 5 & 15 & 17 & 5 & - & - & - & - & 37 & 11 \\
\hline Pair 12 & 6 & 18 & 13 & - & - & - & - & 37 & 11 \\
\hline T. no. NOR & - & 9 & 38 & 28 & 22 & 2 & 4 & 103 & 23 \\
\hline \multicolumn{10}{|l|}{ M. trossulus } \\
\hline Pair 3 & 15 & 22 & 1 & - & - & - & - & 38 & 10 \\
\hline Pair 7 short arm & 10 & 18 & 10 & - & - & - & - & 38 & 10 \\
\hline Pair 7 long arm & 32 & 6 & 0 & - & - & - & - & 38 & 10 \\
\hline Pair 9 & 16 & 6 & 6 & - & - & - & - & 38 & 10 \\
\hline T. no. NOR & - & 8 & 23 & 27 & 3 & 3 & 1 & 69 & 23 \\
\hline
\end{tabular}

T. no. NOR: total number of NORs per metaphase 

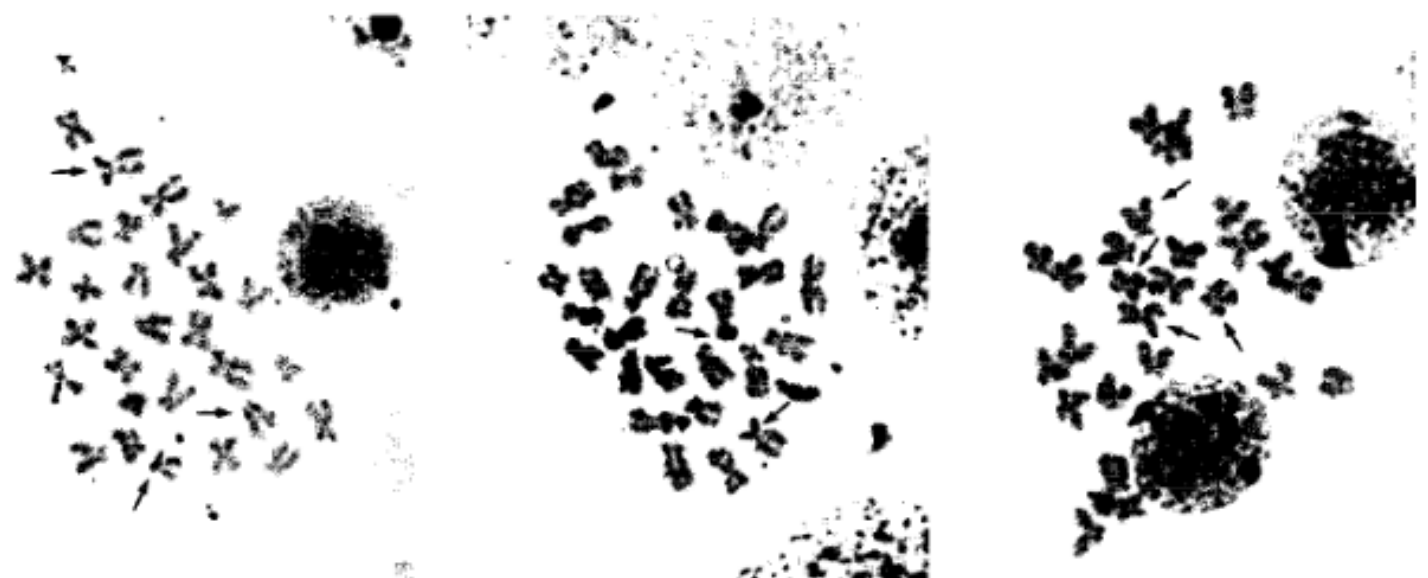

a
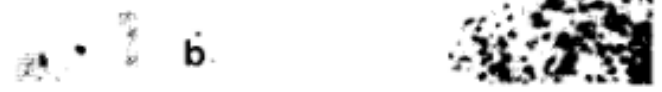

C

Figure 2. Silver-stained metaphases of (a) M. californianus; (b and c) M. trossulus. Arrows show the Ag-NOR regions.

a

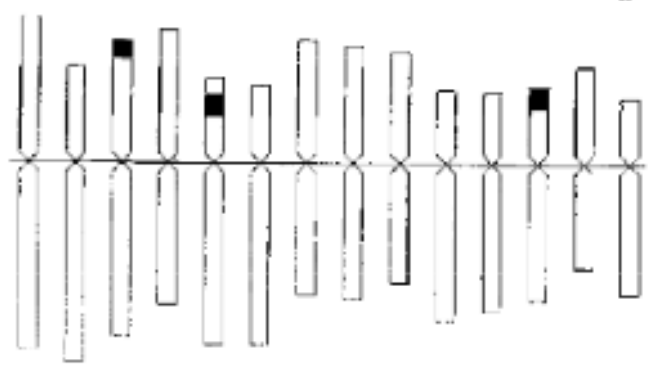

$\begin{array}{llllllllllllll}1 & 2 & 3 & 4 & 5 & 6 & 7 & 8 & 9 & 10 & 11 & 12 & 13 & 14\end{array}$
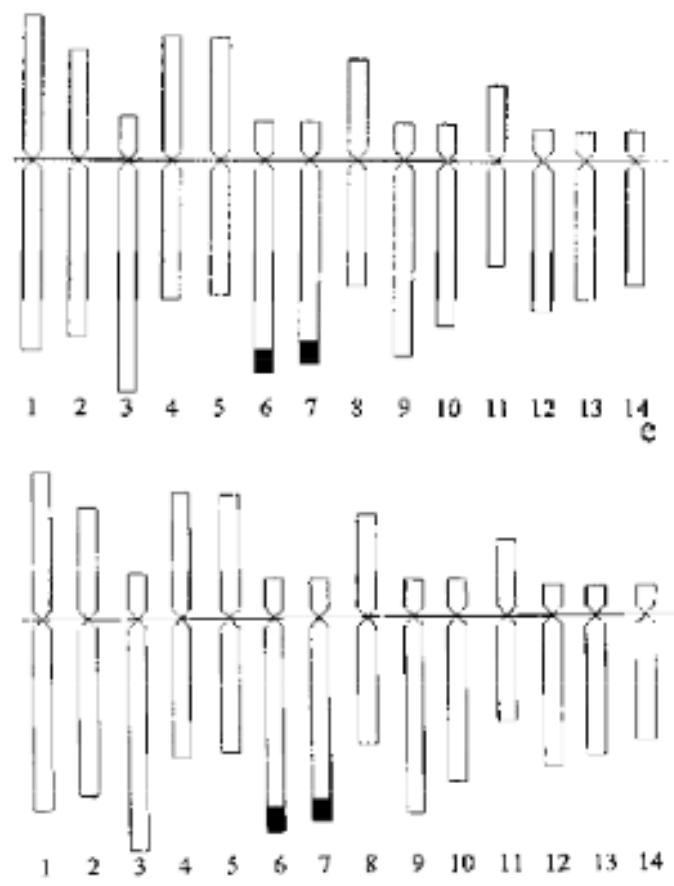

b
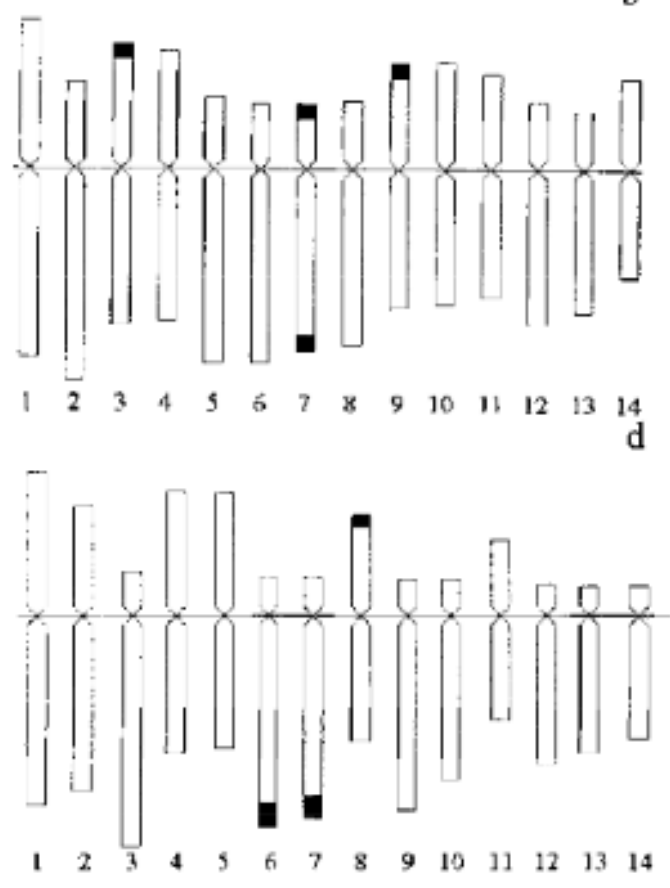

Figure 3. Idiograms of Ag-NORs in (a) M. californianus from the Pacific Canadian coast; (b) M. trossulus from the Pacific Canadian coast; (c) M. edulis from the Atlantic Dutch coast; (d) M. trossulus from the Baltic German coast and (e) M. galloprovincialis from the Atlantic Spanish coast. 


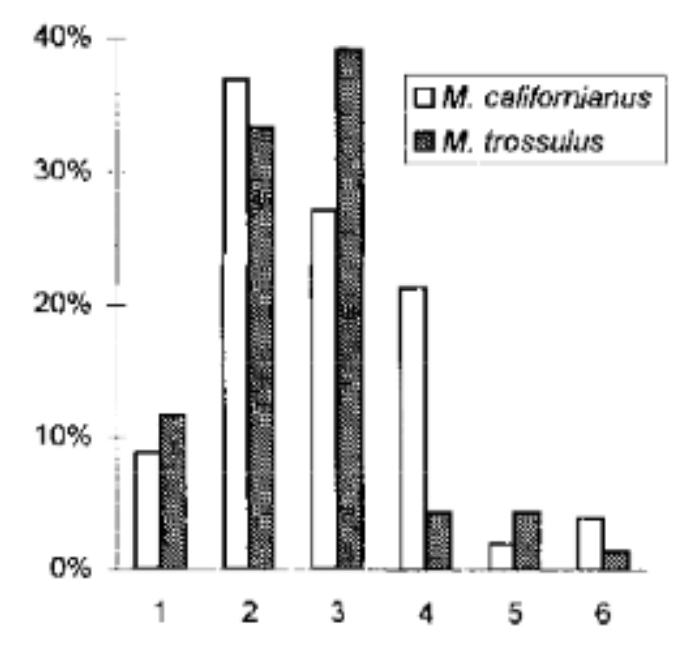

Figure 4. Frequency of metaphases with one to six active NORs in the species studied.

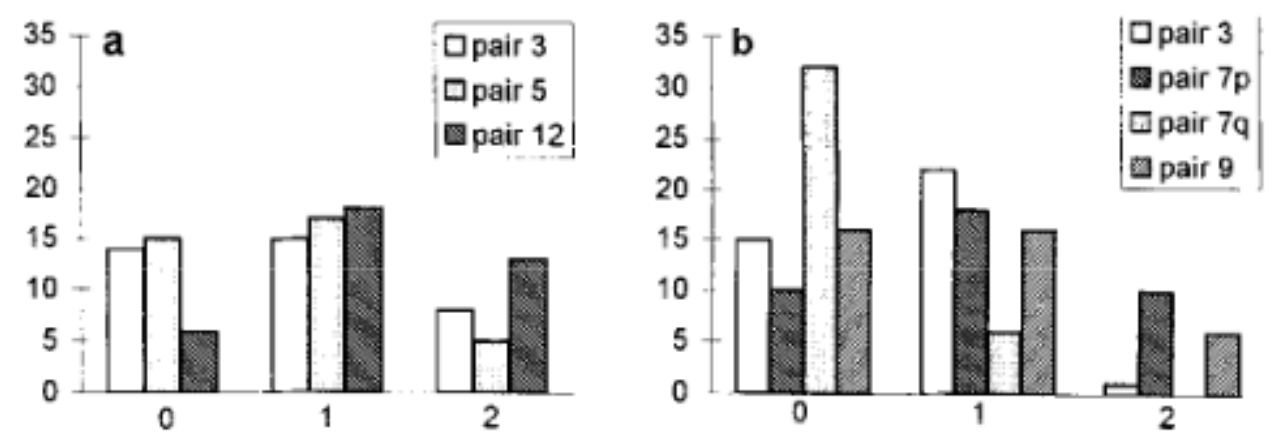

Figure 5. Number of metaphases with 0,1 or 2 active NORs per chromosome pair in (a) M. californianus and (b) M. trossulus.

In M. trossulus, NORs were analyzed in 69 metaphases from 23 individuals (Table 2) and we have observed four Ag-NORs terminally located on the short arms of chromosome pairs Nos. 3 and 9. On chromosome No. 7, Ag-NORs appear located on the telomeres of the short and long arms (Fig. 2b, Fig. 3b). The number of Ag-NORs varies from one to six (Fig. 4, Table 2), with three NORs being the most frequent case. To analyze 38 metaphases from 10 individuals we can observe that Ag-NORs on the telomeres of the short arms of the chromosome Nos. 7 and 9 show high activity. The Ag-NOR on the telomere of chromosome No. 7 shows low activity (Fig. 5b).

\section{Discussion}

We confirm that $M$. californianus and $M$. trossulus show a diploid chromosome number of $2 n=28$. Metaphases above or under 28 chromosomes appear in a very lower proportion. When we determined the amount of DNA in mussel cells, employing flow cytometry, we showed that the amount of DNA is very constant (Méndez et al., unpublished data).

The values obtained for the relative length of individual chromosomes are very similar between the two species. No differences were observed when we compared these values with those obtained in M. edulis, M. galloprovincialis, $M$. trossulus or $M$. desolationis. Maximum values are close to 10 and minimum above 5 (Moynihan and Mahon, 1983; Thiriot-Quiévreux, 1984; Dixon and Flavell, 1986; Pasantes et al., 1990; Insua et al., 1994). The karyotypes of both populations show seven metacentric chromosome pairs and seven submetacentric. These results reflect clear differences in relation to the other populations we have examined. 
In this sense, the karyotypes of different populations of $M$. trossulus from the Baltic Sea consist of six metacentric chromosome pairs and eight submetacentric-subtelocentric (Insua et al., 1994; Martínez-Lage et al., 1995).

The variability observed in the centromeric index values, which are close to 25 (value established by Levan et al., 1964 as limit between submetacentric and subtelocentric chromosomes) could be due to the different degree of condensation of the chromosome arms (amongs other causes). Such variability is accompanied by variations in the classification of the chromosomes from one metaphase to another. So, in M. californianus, generally, the chromosome pairs Nos. 2, 5, 6, 10, 11, 12 and 14 are submetacentric; however, in some metaphases they may appear as subtelocentric; as with chromosome pairs Nos. 2, 5, 6, 7, 8, 12 and 13 of $M$. trossulus.

On the other hand, M. californianus Ag-NORs were found located on the short arms of three chromosome pairs. These locations do not show any similarity with the positions of the Ag-NORs detected in populations of Mytilus from European coasts. Two of the four positions of the Ag-NORs detected in M. trossulus from Canada, were not found in European mussels. In this sense, Insua et al. (1994) and Martínez-Lage et al. (1995) found three Ag-NORs regions in M. trossulus from Baltic Sea. Such regions were terminally located on the long arms of two medium-size chromosome pairs submetacentric-subtelocentric and on the short arm of one medium-size metacentric chromosome pair. As suggested by Martínez-Lage et al. (1995) these chromosome pairs could be Nos. 6, 7 and 8 .

Taking this into account, we could suppose that the chromosome No. 9 of M. trossulus from Canada is equal to the chromosome No. 8 of M. trossulus from Baltic Sea. Similarly, the telomeric region of the long arm of chromosome No. 7 of $M$. trossulus from Canada could be chromosome Nos. 6 or 7 from European populations. However, there is a different location among the populations of M. trossulus from Canada in relation to the other Ag-NOR regions detected in the chromosomes (i.e. located on the short arms of chromosomes 3 and 7). These characteristics are accompanied of different chromosome morphology too. So, although the allozymic data relating to M. trossulus from North Pacific coast and from Baltic Sea suggest that they are a same taxon (Bulnheim and Gosling, 1988; Varvio et al., 1988; McDonald et al., 1991; Väinölä and Hvilsom, 1991), our results suggest that both populations of M. trossulus are clearly different. In this sense, as suggested by Geller et al. (1993) if we assume that the rate of nucleotide substitution in the $16 \mathrm{~S}$ rDNA gene is similar in the different species of Mytilus, M. trossulus is an older species than M. edulis and M. galloprovincialis, and, subsequently, could be supposed that M. edulis on the Atlantic shore of North America may derive from Pacific population of M. trossulus which dispersed through the Arctic Sea in an interglacial or postglacial period (Geller et al., 1993). This idea is supported by the apparent North Pacific origin of much of the North Atlantic marine fauna (Vermeij, 1991, 1992; Reid, 1990). Our results suggest that new chromosome changes may have taken place after mussels settled in new ecological niches from North America to the North Atlantic. These changes were fixed giving rise to the different European taxa. A strong preservation of the primitive chromosome morphology (chromosome Nos. 7 and 8) would take place in the Baltic Sea population. They show a high similarity in the allozyme frequencies, too. However, when M. trossulus frequencies are compared between regions, e.g. the Baltic Sea (Tvärminne) and the west coast of North America (Tillamook), there are large differences between them at most of the analyzed loci (Gosling, 1992). Marked allele frequency differences (no significant values given) between Baltic and Canadian maritime M. trossulus have also been observed at four out the five loci analyzed by Varvio et al. (1988). By all these reasons, we suggest that the mussel populations from Baltic Sea may be considered as a different taxon from $M$. trossulus.

On the other hand, we must point out that Dixon et al. (19861, in M. edulis, found one Ag-NOR on the telomere of a large metacentric chromosome. Martínez-Expósito et al. (1994), analyzing different $M$. galloprovincialis populations from the northwest of Spain, describe the existence of one Ag-NOR (in nine metaphases out of 411) in a large metacentric chromosome. We think that such Ag-NORs could be the same as chromosome No. 3 from M. trossulus. Furthermore, in mussels from Baltic Sea, we have detected two metaphases with a medium size submetacentric-subtelocentric chromosome showing one Ag-NOR on the 
telomere of the short arm (unpublished data). This chromosome could be equivalent to chromosome No. 7 of M. trossulus from Pacific coast.

There is a clear similarity between $M$. californianus and M. trossulus. Their karyotypes are constituted by the same number of metacentric and submetacentric chromosomes; chromosome No. 3 in both species show great similarity, and the chromosome No. 12 from M. californianus and the chromosome No. 7 from $M$. trossulus are very similar, too. These data suggest a greater similarity between $M$. californianus and $M$. trossulus from Pacific coast than exists among European Mytilus species.

In relation to the Ag-NOR activity, it is very similar in both species (Fig. 4), although slightly higher in $M$. trossulus. The values are similar to those reported in the European mussels by Insua et al. (1994) but higher than the values detected in adult mussels populations from northwest of Spain and lower than larvae from the same population (Martínez-Expósito et al., 1994). We must point out that, occasionally, we have detected the existence of six actives Ag-NORs per metaphase (four metaphases of $M$. californianus and one of $M$. trossulus, Table 2).

This analysis shows remarkable differences in the chromosome morphology of mussel Mytilus from Pacific and North Atlantic coasts. It would be very important to analyze the chromosome morphology of Mytilus from American Atlantic coast. Furthermore, we hope that the analysis of satellite DNA, by means of in situ hybridization, which we are performing at present, will provide additional data to clarify the phylogeny of these species of mussel.

\section{Acknowledgements}

We are very grateful to J.L. Littlepage from the Biology Department (University of Victoria) for providing us with the microalgae suspensions used to feed the mussels, and to Phil Rice for carefully reading the manuscript. This work has been supported by a NSERC Grant OGP 0046399 (Canada), a XUGA 10303 B93 and XUGA 10306B95 (Spain).

\section{References}

Ahmed, M. and Sparks, A.K., 1970. Chromosome number, structure and autosomal polymorphism in the marine mussels Mytilus edulis and Mytilus californianus. Biol. Bull., 138: 1-13.

Bulnheim, H.P. and Gosling, E., 1988. Population genetic structure of mussels from the Baltic Sea. Helgoländer Meeresunters, 42: 113-129.

Comet, M., 1993. A short-term culture method for chromosome preparation from somatic tissues of adult mussel (Mytilus edulis). Experientia, 49: 87-90.

Dixon, D.R. and Flavell, N., 1986. A comparative study of the chromosomes of Mytilus edulis and Mytilus galloprovincialis. J. Mar. Biol. Ass. UK, 66: 219-228.

Dixon, D.R., McFadzen, I.R.B. and Sisley, K., 1986. Heterochromatic marker regions (nucleolar organisers) in the chromosomes of the common mussel, Mytilus edulis (Mollusca: Pelecypoda). J. Exp. Mar. Biol. Ecol., 97: 205-212.

Geller, J.B., Carlton, J.T. and Powers, D.A., 1993. Interspecific and intrapopulation variation in mitochondrial ribosomal DNA sequences of Mytilus spp. (Bivalvia: Mollusca). Mol. Mar. Biol. Biotechnol., 2: 44-50.

Gosling, E.M., 1992. Genetics of Mytilus. In: E. Gosling (Editor). The Mussel Mytilus: ecology, physiology, genetics and culture. Elsevier, Amsterdam, pp. 309-382.

Howell, W.M. and Black, D.A., 1980. Controlled silver-staining of nucleolar organizer regions with a protective colloidal developer: a l-step method. Experientia, 36: 1014-1015.

Ieyama, H., 1983. Karyotype in Mytilus edulis (Bivalvia, Mytilidae). Mem. Facul. Edu. Ehime Univ., 3: $23-$ 26. 
Insua, A., Labat, J.P. and Thiriot-Quiévreux, C., 1994. Comparative analysis of karyotypes and nucleolar organizer regions in different populations of Mytilus trossulus, Mytilus edulis and Mytilus galloprovincialis. J. Moll. Stud., 60: 359-370.

Levan, A., Fredga, K. and Sandberg, A.A., 1964. Nomenclature for centrometic position on chromosomes. Hereditas, 52: 201-220.

Martínez-Expósito. M.J., Pasantes, J.J. and Méndez, J., 1994. NOR activity in larval and adult mussel Mytilus galloprovincialis Lmk. J. Exp. Mar. Biol. Ecol., 94: 155-165.

Martínez-Lage, A., Gonzalez-Tizón, A. and Méndez, J., 1994. Characterization of different chromatin types in Mytilus galloprovincialis Lmk. after C-banding, fluorochrome and restriction endonuclease treatments. Heredity, 72: 242-249.

Martínez-Lage, A., Gonzalez-Tizón, A. and Méndez, J., 1995. Chromosomal markers in three species of the genus Mytilus (Mollusca: Bivalvia). Heredity, 74: 369-375.

McDonald, J.H. and Koehn, R.K., 1988. The mussels Mytilus galloprovincialis and Mytilus trossulus on the Pacific coast of North America. Mar. Biol., 99: 111-118.

McDonald, J.H., Seed, R. and Koehn, R.K., 1991. Allozyme and morphometric characters of three species of Mytilus in the Northern and Southern Hemispheres. Mar. Biol., 111: 323-335.

Méndez, J., Pasantes, J.J. and Martinez-Expósito, M.J., 1990. Banding pattern of mussel (Mytilus galloprovincialis) chromosomes induced by 2 x SSc/ Giemsa-stain treatment. Mar. Biol., 106: 375377.

Moynihan, E.P. and Mahon, G.A.T., 1983. Quantitative karyotype analysis in the mussel Mytilus edulis L. Aquaculture, 33: 301-309.

Pasantes, J.J., Martínez-Expósito, M.J., Martínez-Lage, A. and Méndez, J., 1990. Chromosomes of Galician mussels. J. Mall. Stud., 56: 123-126.

Reid, D.G., 1990. Trans-Arctic migration and speciation induced by climatic change: the biogeography of Littorina (Mollusca: Gastropoda). Bull. Mar. Sci., 47: 35-49.

Sarver, S.K. and Foltz, D.W., 1993. Genetic population structure of a species complex of blue mussels (Mytilus spp.). Mar. Biol., 117: 105-112.

Seed, R., 1976. Ecology. In: B.L. Bayne (Editor). Marine Mussels: Their Ecology and Physiology. International Biological Programme 10. Cambridge University Press, Cambridge, pp. 13-65.

Seed, R., 1992. Systematic evolution and distribution of mussels belonging to the genus Mytilus: an overview. Am. Malac. Bull., 9: 123-137.

Soot-Ryen, T., 1955. A report on the family Mytilidae (Pelecypoda). Allan Hancock Pacif. Exped., 20: 1175.

Thiriot-Quiévreux, C., 1984. Chromosome analysis of three species of Mytilus (Bivalvia: Mytilidae). Mar. Biol. Lett., 5: 265-273.

Väinölä, R. and Hvilsom, M.M., 1991. Genetic divergence and a hybrid zone between Baltic and North Sea Mytilus populations (Mytilidae; Molluscal. Biol. J. Linn. Soc., 43: 127-148.

Varvio, S.L., Koehn, R.K. and Väinölä, R., 1988. Evolutionary genetics of the Mytilus edulis complex in the North Atlantic region. Mar. Biol., 98: 51-60.

Vermeij, G.J., 1991. Anatomy of an invasion: the trans-Arctic interchange. Paleobiology, 17: 281-307.

Vermeij, G.J., 1992. Trans-equatorial connections between biotas in the temperate eastern Atlantic. Mar. Biol., 112: 343-348.

\footnotetext{
*fina@udc.es
} 